This article has been scanned by iThenticat No plagiarism detected

Volume 3, Issue 2, April 2021

p. 74-86

\title{
A STUDY OF TENSE SHIFT AS A RESOURCE FOR IDENTITY CONSTRUCTION
}

http://dx.doi.org/10.47832/2757-5403.2-3.7

Shatha N. QAIWER ${ }^{1}$

\begin{abstract}
:
This study focuses on tense variation as linguistic features of narrative performance using Schiffrin's (1981) theory of tense variation supported by Labov's (1972) and Ochs and Cap's (2001) frameworks of narrative structure. It shows that historical present also performs evaluative function and appears in restricted clauses in progressive aspect indicating the overlap on time between two actions. Shifts into narrative past tense also perform an evaluative function and appears in contexts narrating unexpected event within the complication. Generic and nominalising actions are used to express negative evaluation of an opponent based on an earlier premise. These findings can bring new insights into the way politicians construct arguments in self and other presentation since nominalising negative actions implies comparing the self to an external other. This is achieved in association with stance taking and evaluative commentaries provided by politicians as strategies of positive self and negative other presentation. The study provides a detailed analysis of the linguistic features stated earlier in relation to identity construction and self-presentation exemplifying the use of HP.
\end{abstract}

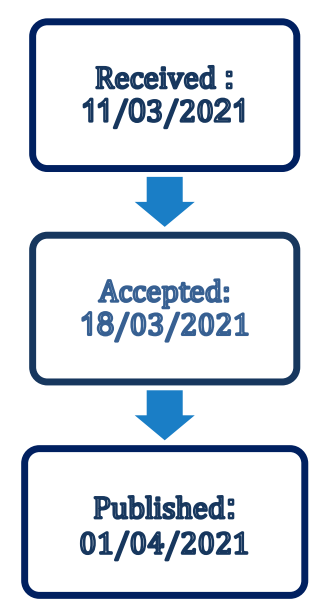

Key words: Discourse, Narrative, Historical Present, Narrative-Based Discourse Study.

\footnotetext{
${ }^{1}$ Dr. , Baghdad University, Iraq, shatha.naiyf@coeduw.uobaghdad.edu.iq, https://orcid.org/0000-0001-7855$\underline{1601}$
}

Copyright (C) Published by IJHER Journal, www.ijherjournal.com Rimar Academy, Fatih, Istanbul, 34093 Turkey

All rights reserved 


\section{Introduction}

Narratives have a teller and a trajectory: They are expected to 'go' somewhere with a point and resolution. They have beginnings, middles and ends, and include the recounting of events that are displaced spatially, and, crucially, temporally. For a stretch of talk or text to be categorized as 'narrative', it has to incorporate basic structural features, including a narrator, characters, settings, plot, events that evolve over time, crises and resolutions. Toolan $(2001$, p. 8) states that narratives contain the following six characteristics:

1. A degree of artificial fabrication or constructedness that we do not usually find in spontaneous conversation, but is pre-planned with previous performance of it;

2. A degree of prefabrication-narratives contain bits that we have seen or heard before;

3. A trajectory-narratives go somewhere and are expected to go somewhere with development and a resolution or conclusion provided;

4. A teller who is always important no matter how back-grounded or invisible

5. Narratives richly exploit displacement, which is the ability of human language to refer to things or events that are removed in space or time from the speaker or the addressee; and

6. Recall of events and happening that may be remote from the teller and his audience not only spatially, but also temporally (p. 4-5).

Performing narrative analysis depends on the purpose behind producing a narrative. Narrative can be considered as an argumentative component (Voss, Wiley and Sandak, 1999, p.237) when used persuasively. Narratives also serve an organizing principle of human action (Sarbin 1986, p. 9) when describing the mental act of sense making and meaning-making as a cognitive process of meaning making and sense making (Bruner, 1990). In the political domain, narrative can be defined as the organization of thought through language, internalized or externalized, which serves to create a sense of personal coherence and collective solidarity and to legitimize collective beliefs, emotions, and actions' (Hammack and Pilecki, 2012, p.78).

Benwell and Stokoe (2006: 143) state that narrative analysis is a way of examining people's lives through the stories they tell. They (p. 42) consider it as an effective analytical tool that mixes macro- and micro- levels of analysis, and further specify what they consider as the central features required for characterising a piece of discourse as a narrative (p.133).

Although many studies conduct narrative analysis, there is no universally agreed way for exploring the target data under scrutiny. As observed by Riessman $(1993, \mathrm{p}$. v), the previous work performed in the field 'remains silent' about ways of approaching long extracts of spoken and written discourse possessing narrative form (Cited in Benwell and Stokoe, 2006, p. 142). This implies that there is no single correct way of approaching data. In exploring self-presentation, the study combines the Labovian framework as representation of the structural aspect of narratives with Ochs and Capps' approach, which focuses on narrative content and also traces where tense shifts occur in terms of structure and content. Following the same frameworks in identifying narratives, the researcher explores the role of discourse presentation in both foregrounding and backgrounding identity claims, and in highlighting self-presentation.

\section{Narrative Historical Present}

The historical present tense (HP) refers to events which began and ended at some point previous to the moment at which the narrative is being told'; this verbal tense is common in narrative discourse, and is often referred to as 'dramatic' or 'conversational' narrative present (Wolfson 1982, p. 3). Using HP can alternate with the simple past tense without change in the referential meaning. Wolfson $(1987$, p. 216) argues that it is one of several 'performative' features of oral narrative, occurring in conjunction with other performative devices such as direct speech, motions and gestures, asides, repetition, expressive sounds, and sound effects. The function of this performative feature is to describe the experience from the speaker's point of view, and to 'dramatize' it. It; therefore, encodes 'shifts between the story world and the interactional world' to indicate involvement or distancing in relation to the interlocutors and/or the narrated events (De Fina 2003, p. 24). These linguistic techniques of performance relate to the 'internal evaluation' in Labov's framework.

Shifts in tense involve not only simple verbal forms, but also the aspectual forms appearing within the perfective and progressive tenses. The HP substitutes past tense and past 
progressives to express duration and imperfective aspect with no change in reference. Although Wolfson's (1987, p. 216) definition states that both tenses report events that occurred in the past, I follow Fleischman $(1991$, p. 82) in taking the stance that they are not equivalent, since the selection of the present tense in narratives always involves some special information. As the tense of narrative discourse is almost always in the past, the use of the present serves to report events that are happening in front of the speakers' eyes to bring vivid illustration of the movement of the events to the audience. This can be true for texts produced for persuasive purposes, and not in other naturally-occurring narratives which do contain shifts to historical present. This may be one of the reasons that this view has been rejected by Comrie (1986) and Fludernik (1991) as well, because historical present has 'one particular meaning and they additionally imply that whenever the context is as specified, the present tense must occur' (Fludernik 1991, p. 367).

In a study of tense shift in 'danger of death' narratives, Harvey (1986) shows, in contrast to Wolfson's (1982) claims that HP are used to make the audience feel they are reliving the experience, that HP signals that the narrator is unconsciously reliving an intensely personal experience. The use of HP may thus serve to signal to the audience the arrival of the crucial part of a story, or the purpose underlying its telling. The focus on HP in this study is mainly driven by the fact that this linguistic phenomenon is related to other ones such as reported speech which involves tense shifts and as the analyses shows instances where a reported speech construction involves HP. Similarly, Harvey (1986) provides instances of close danger speeches where the teller of a story uses HP in reporting his wife's utterances and his own utterances. Although some events are reported in past tense construction, other descriptions involve using existential processes with HP 'there is ...' In conclusion; HP is a performative feature of narratives that makes the narratives worth of study.

\section{Analytical Approaches to Narrative}

A narrative is a genre of discourse, consisting of telling a story in a temporal sequence and involving characters, events and actions; that is, the retelling of past events with the purpose of expressing a viewpoint about and of the speaker. This definition is in line with a more sociolinguistically-oriented definition stated as 'all the stories are associated discourse units, such as explanations and chronicles, and the connection between them, told by an individual during the course of his or her lifetime' (Linde 1993, p. 21). She further indicates that stories which make a point about the speaker, not the world, are tellable (i.e. they have a reason to be told).

The definition of narrative is based on to the two dimensions emphasised by Ochs and Capps (1996, p. 23-24) as essential to any narrative: temporality and point of view. The authors state a 'multiplicity of selves' can be represented in the same story. In narrating stories in temporal sequence with additional evaluative remarks, people represent their 'selves' in relation to their emotional and physical environment and through which they 'come to know [themselves], apprehend experiences and navigate relationships with others' (p. 21-22).

Labov (1972, p.359-60) identifies six categories, each of which serves to address a hypothetical question about narrative structure and fulfils a different function:

1. ABSTRACT (What was this about?)

2. ORIENTATION (Who is involved in the story, and when and where did it take place?).

3. COMPLICATING ACTION (Then what happened?)

4. RESOLUTION (What finally happened?)

5. EVALUATION (So what?)

6. CODA (How does it all end?)

Ochs and Capps' (2001, p.173) list of narrative components is added here because it has more to provide regarding the inner state of the protagonist and his/her unplanned action. It provides the angle through which the analyst can examine how the self is reflected in the narrative. The list starts with the following: Setting, unexpected event, physchological or physical response, unplanned action, an attempt, a consequence. 


\section{Methodology}

This study includes a narrative analysis of Obama's De Moines Speech on Election night. The researcher conducts a qualitative analysis of the selected narrative using Labov's (1972) framework of elements of oral narratives, combined with those of Ochs and Capps (2001). The reason for this combination is that Labov's elements are largely structural in focus, which alone does not seem to contribute as much to the construction of identity within texts. Ochs and Capps' elements, by contrast, reflect the content of narratives much more than their structural components.

The aim of conducting narrative analysis is to see how Obama constructs different identities and positive self-presentation. This text involves an 'interactive' narrative in that it allows for personalised engagement between the speaker and the audience, thus narrowing the gap between interlocutors. I use the word 'interactive' because I have observed that Obama uses linguistic elements that reflect the features of a conversation such as you know, or the direct address of the audience through the second person pronoun you. The presence of conversational features is contextually unsurprising, because the narrative is delivered as a part of formal speech where audience interaction is considered fairly important.

The narrative approach utilised adopts the view that narrative analysis should examine not only structural features but also the sociolinguistic elements surrounding them (Gimenez, 2010 , p.199). Studying narratives can reveal psychosocial functions, the most significant of which is maintaining a sense of identity and self-empowerment (Viney and Bousfield, 1991). In conducting the narrative analysis in this study, the researcher argues that political speeches are a significant arena through which identity is constituted and reconstituted. The study therefore examined identity construction through stylistic variation as it is considered a strategic means by which speakers can activate meaning potential and construct identity at different points in the sequence of discourse (Coupland, 2001). Based on this view, the narrative analysis presented shows that there are context shifts accompanying shifts in verbal tense.

\section{Analysis}

In this section, I aim to examine which clause type the historical present alternates with the past and how it relates to self-presentation. In order to achieve this goal, a structural analysis is required. As above, Labov's framework of structural analysis of clauses in narratives is employed to trace the tense shift according to clause type and in the components of the narrative. It should be noted that this text is an election campaign speech and addressed to the public crowds on the intersection of East 4th and East Locust Streets. Obama made an emotional plea to his supporters not to "give up on change" as he staged his final re-election rally in Iowa. The story he narrates in this text shows the crowd how Edith's (councilwoman from Greenwood) actions managed to change the atmosphere of the room where he was holding a meeting in Greenwood. I have chosen this text because of its importance as it reveals Obama's personal experience that he repeats on several occasions. At the beginning, the verbs occurring in HP form are identified and classified into their process types to see which group occurs in both HP and narrative past and which do not. Although this is examined in one text and it may not reflect the way these verbs behave in other texts, it may provide a useful starting point for research in tense variation. Table1. below shows the verbs occurring in HP in the Des Moines text.

Table 1 Verbs shifting into historical present in the selected narrative (Des Moines 2012)

\begin{tabular}{|l|l|l|l|l|}
\hline $\begin{array}{l}\text { Movement } \\
\text { (action) }\end{array}$ & Mental & Senses & Habitual & Other \\
\hline land & think & hear & get coffee & grinning \\
\hline taps & feel & look & get dressed & smiling \\
\hline drive & know & looking & go downstairs & showing me up \\
\hline drive out & wondering & asking & wake up & peering at \\
\hline pull up & thinking & & take a shower & \\
\hline
\end{tabular}




\begin{tabular}{|l|l|l|l|l|}
\hline blows open & feeling & & & \\
\hline goes & & & & \\
\hline travelling & & & & \\
\hline dragging & & & & \\
\hline walking & & & & \\
\hline $\begin{array}{l}\text { shaking } \\
\text { hands }\end{array}$ & & & & \\
\hline running & & & & \\
\hline $\begin{array}{l}\text { making my } \\
\text { way }\end{array}$ & & & & \\
\hline
\end{tabular}

The sets of groups mentioned in Table 1 above are interrelated. Most of the verbs are verbs depicting movement, mental states and describing people and their actions. Therefore, there may be a relation between tense choice and process type involved. Thus far, I have stated that the historical present occurs in linguistic contexts that have a present time understanding and that it can have a progressive form if the event involves the present moment of speaking, whether in the story world or the social one. Fludernik (1991, p. 368) states that the historical present occurs only in the 'complicating action' section of the narrative and it is rarely found in 'abstract, (embedded) orientation, or coda.' The following analysis attempts to identify the occurrence of tense shift in the narrative components as specified by Labov.

\section{Abstract}

The abstract signals that the story is about to begin and brings to the listener's attention that the teller has a story to tell. Toolan $(2001$, p. 150) prefers to say that it outlines or advertises that a story will follow rather than saying that the teller intends to tell a story, because one person may produce the abstract and leave the floor to someone else to tell the whole story. In the present study, Obama is the only person who delivers his speeches; therefore, the following extract advertises that Obama himself has a story to tell:

\section{Example 1}

1. I got a powerful reminder of this myself on our last campaign.

2. (a) Folks in Iowa, I know you may have heard this story 2(b) but it was early in the primaries, and we were still way down in the polls.

3. I think this office had just finally gotten the heat turned on.

4. And at the time, I was still competing in South Carolina - it was one of the early primary states. And I really wanted the endorsement of a state representative down there.

In 1 , Obama starts telling the story and indicates in 2(a) that this is not the first time he has told it. The coordinator but in 2(b) indicates that Obama has more to add to it and a friendly request and insistence upon the tellability of the narrative whose start is marked with the narrative past in it was. Sentence 3 starts with the present tense I think but this is not historical present because it reflects his evaluation of the proposition. Obama uses it to introduce a clause describing an event in the past tense had just finally gotten the heat turned on; I think indicates his mitigation of the truth of the proposition made at the moment of speaking. Then he uses narrative past in the clauses that follow. So from 2(b), the story starts in past tense and there is no shift into historical present tense. This finding 
supports Fludernik's (1991, p. 368) claim stated earlier that HP is rarely found in the abstracts.

\section{Orientation}

After describing the first context in which Obama asked for endorsement and made his promise (reported in past tense), Obama shifts into the present, indicating the shift into a different scene with different time and place (embedded orientation). The following extract marks the beginning of a new scene:

\section{Example 2}

1. (a) So it's about a month later, (b) and I'm traveling back to South Carolina.

2. (a) And we flew in late - (b) I think we were coming from Iowa.

3. We had been campaigning non-stop, traveling all through towns and having town hall meetings and shaking hands.

4. And in between, I'm making phone calls, asking people for support.

5. And so we land in Greenwood, South Carolina, at around midnight.

6 . We get to the hotel about 1 o'clock in the morning.

7. I am wiped out.

8. I'm exhausted.

9. And I'm dragging my bags to my room.

10. Back then we didn't fly on Air Force One. And the accommodations were a little different.

Sentence 1 in the above extract orients the listeners to a new time and place and is marked with a shift into historical present. Another shift appears with I think in clause 2(b) introducing a clause with a past tense verb were coming from Iowa. Clause $2(\mathrm{~b})$ is a free clause that can be displaced without disrupting the event sequence as it provides background information to the narrative. Therefore, the shift from the narrative past tense flew in into the present I think is justified because it shows that Obama is addressing the listeners rather than continuing the story. This is in line with the tense shift noted in Example 3 above. This finding is significant for the purpose of the study as it shows that cognitive verbs (e.g. think, wonder) are used in present tense when they are used in free clauses that are meant to add background information to the story.

Sentences 3 and 4 are temporally anchored because I am making phone calls and asking people for support overlap with the event in 3 . Thus, 4 is a restricted clause because it cannot be removed without changing the semantic interpretation. We can see that it involves a shift from had been in 3 into I'm making phone calls, asking people for support, providing the image of a busy figure working towards his goal for the sake of his people. This finding further illustrates that the tense shifts into present progressive in restricted clauses when providing background information. As noted, the tense shifts from past into progressive to indicate that the two actions overlap in time. If we omit 3 and 4 , we can see that 5 and 6 are a continuation of the narrative that started with 2(a) we flew in late. Clauses 5 and 6 take the listeners back to the orientation. The underlined verbs land and get to (Table 1) cluster at the beginning of new scene in a new place (Greenwood) and time (at around midnight); they are action verbs implying movement with historical present form. Sentences 7 and 8 are coordinated clauses whose reported event time overlaps with the verb in clause 9. The present progressive dragging in 9 denotes movement and scheduled activity. Clause 9 is temporally ordered, but not strictly; that is, its displacement is restricted by and. It can be placed before 8 and 7 but not any further because its time event overlaps with these adjacent clauses $(8,7)$. This clause is part of the narrative and different from the progressive in 4 which adds extra information to the narrative. We can note that in both examples the present progressive occurs in a restricted clause. With clause 9, the progressive is introducing unexpected events in another setting.

As a significant finding in political communication, tense shift in sentences such as these create interpersonal involvement (self and listeners) through which hearers can insert themselves into an event and experience what took place through sharing with the speaker contextualised cues (Schiffrin, 1997: 41). The reference time of the progressive verb dragging includes the moment of speaking in the story world. Schiffrin (1981: 57) states that action verbs occur in progressive form in restricted clauses, leading to 'complicating action clauses whose event time is limited to an overlap with a few adjacent clauses'. The action verbs in 
the example above and the progressive verb dragging are followed by the narration of the unexpected event in the extract that follows, which includes the physical and emotional reaction of the narrator. If we omit sentence 10 as it provides background information and is not part of the narration, we can see that the progressive verb dragging is followed by the narration of the unexpected event:

\section{Example 3}

And just as I'm about to walk into the room, one of my staff taps me on the shoulder to say, "Excuse me, Senator" --I was a senator back then. "We're going to have to wake up and be on the road at 6:30 a.m. in the morning." And I said, "What?" "Why?" "Well, you made this promise to go to Greenwood, and it's several hours away." And you know, Iowa, I try to keep my promises.

In the example above, Obama introduces another setting of the unexpected event. The tense of the narration is shifted into historical present as the underlined verbs I'm and taps show. As an action verb, taps describes the relationship between the employer (Senator) and a member of the staff. This finding is significant as the shift and the semantic implication of the verb is meant to draw an image of the managerial figure of the president who listens and acts collaboratively with people of less powerful positions such as his staff members. This interpersonal relationship is extended from the employer/employee in the story world into the social world, locating the institutional identity of Obama as a president with whom people are acquainted through the use of you know as a promise-keeper politician and as a maintainer of personal connection with his staff and people. He uses a discourse marker you know in order to signal a breakage in the flow of events and at the same time, in a selfevaluative attempt, the speaker tries to assure his credibility in what promises he made to his nation. The emphatic use of you know highlights the self-identity claim proposed as a promise keeper and indicates the familiarity of the people with the teller.

\section{Complicating Action}

Thus far, we can note that the shifts into historical present tend to cluster at the beginning of each setting introduced in the text and in the complication. The following example can be labelled as unexpected events and complicating actions, includes a shift from historical present to past and the aspect is further shifted to perfective in the last three sentences:

\section{Example 4}

1. So a few hours later, I wake up -

2. and I'm feeling terrible.

3. I think a cold is coming on.

4. And I open up the curtains to try to get some light to wake me up, but it's pouring down rain.

5. Terrible storm.

6. And I take a shower and get some coffee, and I open up the newspaper

7. and there's a bad story about me in The New York Times.

8. I was much more sensitive at that time to bad stories.

9. I've become more accustomed to these now.

The shifts in the last three successive sentences follow reporting habitual events in: taking a shower, having coffee while reading a newspaper. These actions along with the use of you know draws the attention to the personalisation and conversationalisation of political discourse as Obama here shares very personal details with the people. Then an unexpected event functioning as an implied complicating action within the narrative leads the speaker to shift from the historical present there is a bad story to the past tense I was much more sensitive, reporting his reaction towards the same event in that past state of affairs and extending the events to the present perfect I have become more accustomed where the speaker's reaction towards the same event has changed. The perfect tense is a grammatical form used to describe a past event with present relevance, or a present state resulting from a past situation. These events mark the change of the narrator's state and position over time 
by shifting from the HP into the past. This shift is a significant finding since inserting this self-evaluative comment in the middle of a story plays a role in presenting the self positively in a dramatically narrated extract to maximise its effect on the listeners and to keep the image of the protagonist who keeps promises in the story associated with the teller at the present time. In this way, both roles - the narrator and the protagonist, are attached to the positive image of the future president who braves the unknown to keep a promise.

Let us look at the last sentences where this series of shifts takes place:

I open the newspaper and there is a bad story about me. I was more sensitive at that time to bad stories. I have become more...

In the above sentence, the historical present there is alternates with the narrative past I was. Schiffrin (1981, p. 56) shows that 'the shift from historical present to past is more frequent when clauses are introduced by temporal conjunctions... it is only when tense switches from HP to P that events are separated'. The shift in this example is justified in relation to Schiffrin's quotation in two respects: first, although there is no temporal conjunction in the above example, the adverbial at that time indicates the reported action as taking place at the same corresponding time in which the negative story is discovered which in turn maximises the intensity of the complication producing the climatic emotional effect on the recipient in the interactional world. Then, another external evaluation is reported in present perfect tense to depict the image of a powerful experienced self. Second, Schiffrin (1981, p.56.) further indicates that evidence for the same conclusion (which does NOT hold for conjoined clauses) is the relationship between tense- switching and the subject of the clause - if the subject is different from that of the prior clause, tense is more likely to switch from historical present to past, but not the other way around. Although the sentences are not conjoined, the events reported do happen at a corresponding time, in addition to the different subjects of the clauses which justify the shift in tense from historical present to past. The last sentence with its verb in the perfective aspect serves to connect the selfevaluative event become more accustomed... with main narrative event reported and the extended event I was more sensitive to... Schiffrin (1981, p. 50) indicates that aspect is a connector that relates one narrative event to another. In these three sentences, all the events to an extent overlap in time.

In the following extract, it is noted that the progressive form co-occurs with the present form even when the actions in the present tense have a time reference prior to the time of the speaking; again it introduces the narration of an unexpected action:

\section{Example 5}

1. And finally I get dressed, I go downstairs and I'm walking out to the car, and my umbrella blows open -- and I'm soaked.

2. So by the time I'm in the car I'm wet and I'm mad and I'm still kind of sleepy.

In the extract above, the shift into present progressive aspect I'm walking follows the habitual activities in get dressed and go downstairs. The successive flow of the reported actions is presented in a number of coordinated clauses in 2. The action of the event time in the progressive form overlaps with the unexpected event my umbrella blows open and the third clause I'm soaked to describe the result of the preceding action. The emotional state and psychological reaction towards the unplanned event I am mad is provided in sentence 2 .

In Example 6 below, we can see that the inspection I'm looking around occurs in a restricted clause whose time overlaps with the perception process in I don't hear a lot going on. Note the shift into present progressive looking around and the simple present I don't hear a lot from the present and past tense verbs which denote movement and actions pull up and walked in and from walked in into there are 20 people. This means that the shift into historical present accompanies the introduction of new setting and new characters.

\section{Example 6}

1. And so we drive, and we drive, and we drive, and we drive.

2. And finally we get to Greenwood -

3. although you don't know you're in Greenwood right away because there are not a lot of tall buildings around.

4. And we pull up to a small field house, and I walked in, and I'm looking around.

5. I don't hear a lot going on.

6. And the state representative said she was going to organize a little meeting for us, 
7. and we walked in and there are about 20 people there.

8. And they're all, kind of wet, too, and they don't look very excited to see me.

The repetition of drive in 1 implies the long distance and hardship of the journey and serves as a transition to a new scene. Though the above extract starts with the present tense, clause 3 is added to communicate a generic narrative describing the city of Greenwood. This performs the function of an external evaluation as the speaker breaks the flow of the story to address the listeners and it provides extra information about the narrative. The generic clause indicates a claim on Obama's part about his inability to recognise the place immediately, which communicates indirectly his readiness to get that far for a common and noble purpose. The generic clause seems to back up such evaluation. The underlined sentences represent an internal evaluation of the situation as they provide extra information that contributes to the point of the story narrated. Thus, the shift from the past of an action verb into the negated present tense of hear in 5 communicates Obama's evaluation as he describes the setting. Toolan (2001, p. 156) classifies negation expressions as a sub-division of internal evaluation devices called 'comparators'. He further states that 'comparators evaluate indirectly by drawing attention away from what actually happened by alluding to what might have but did not happen'. In 7 , the verb walked in is repeated and the tense shifts into present there are when describing new characters. The intensifier all in 8 provides a further direct evaluation with the expression of negation they do not look very excited. To enhance the point previously stated, the shift in tense occurs when the narrator provides an external evaluation and when he uses internal evaluative devices such as the ones in 5 and 7 . Sentence 5 is a restricted clause - it cannot be moved without affecting the sequence of the narrative. Sentences 7 and 8 are narrative clauses with a temporal juncture. Schiffrin (1981, p.59) labels such clauses as internal evaluative clauses. The historical present in these clauses facilitates presenting events as if they were occurring at that moment, and enables the listeners to hear for themselves what happened, and interpret the significance of those events for the experience. The discussion presented so far adds to the significance of the vivid effect the historical present may have on listeners and supports the claim proposed by Fludernik $(1991$, p. 367) that the historical present has 'one particular meaning and [it] additionally impl[ies] that whenever the context is specified, the present tense must occur'.

In Example 7 below, the speaker produces a short narrative describing his reaction and the way he deals with the situational context in that small room with a few people who do not look excited. Sentence 2 is a narrative one with temporally ordered dependent clauses. Note that the time of the action verb making my way in $2(a)$ is present progressive overlaps with the time of the sense verb hear in $2(\mathrm{~b})$.

\section{Example 7}

1. A. But I'm running for President, so I do what I'm supposed to do - 1(b)and I'm shaking hands, I say, "How do you do? Nice to meet you." 2(a) And I'm making my way around the room, 2(b) and suddenly I hear this voice cry out behind me: "Fired up."

Greeting people is represented, in the above example, as an expected action on Obama's part as he is running for president and must introduce himself to people in that setting. This action reports Obama's attempt to solve the unexpected behaviour reported in Example 8 above specifically in clauses 5 and 7 where it seems that not much was prepared to receive Obama and the 20 people who did not seem excited. Therefore, he tries to approach and greet them based on the evaluation he develops in these two clauses.

Through narrating the attempt, Obama is situating or constructing his own identity as a campaigning politician according to the way he portrays himself in the interactional world. $\mathrm{He}$ is transforming his knowledge of the social world and his own experience through performing his identity. He reflects on greeting people as a normal way of creating rapport with the public. His image as a campaigner is illustrated in the narrative through How do you do? Nice to meet you which performs a categorisation function as it depicts social behaviour, illustrating a meta-discursive comment and giving a concrete form of how Obama and others expect him to behave as a politician running for the presidency. This finding implies that such action serves to function as self-aggrandisement (Labov and 
Waletzky 1967, p. 38), showing himself in a favourable position as compared to the people he met. The progressive form in this extract serves as an evaluative device, visualising the way the speaker views himself as situated within an ongoing interactional context. Not to forget that it breaks the sequence of actions, calling the listeners' attention to that part of the narrative indicating that it has some connection with the evaluative point (Labov 1972, p. 374).

A different type of embedded evaluation is accompanied by the shifts in tense in the example below:

\section{Example 8}

1. I look around, I turned behind me - there's this small woman.

2. She's about 60 years old; looks like she just came from church -

3. she got a big church hat.

4. And she's looking at me, kind of peering at me, and she's grinning, smiling, looking happy.

5. Turns out she's a city councilwoman from Greenwood - who also moonlights as a private detective.

Sentence 1 consists of two coordinated clauses with a shift in tense from present to past. Note that sense verb look appears in its present tense which indicates that sense verbs tend to have the present forms when describing setting and evaluation in the text, as in I do not hear a lot going on and and I am looking around in Example 7 above. This is true of the underlined clause above. Action and movement verbs, on the other hand, may take past and historical present construction depending on the context in which they are introduced. Take, for example, the point made earlier when they cluster at the beginning of new settings and scenes, such as drive, pull up and taps, or when the narrator describes the appearance of new characters in the scene as in the second part of sentences 1-3 and 5 in the extract above. When describing the character this small woman, the progressives looking at, peering at, grinning, smiling, and looking describe the woman's successive facial actions in a single dependent clause. When the progressives are used in such a structure, they are considered as internal evaluation devices called 'correlatives' (Schiffrin 1981, p. 59), as they perform the function of emphasising the simultaneity of distinct action (Toolan 2001, p. 156). They align an event with other events occurring at the same time (Labov 1972, p.387).

As stated earlier, Obama shifts into historical present tense when narrating a new scene, or describing himself or other characters in the story. Similar findings have been evident in a study by Leung (2008), who studies the narrative function and verbal aspects of the historical present in the fourth Gospel. Leung (2008: 713) observes that historical present examples cluster at the opening and closing sections of the story on the one hand, and that shift into historical present accompanying the appearance of each main character in the story on the other hand. Leung's study results categorise historical present verbs, among which are verbs indicating motions and movement.

\section{Evaluation}

The following extract illustrates the achievement of the main point of the story. It describes the repercussion of the psychological and physiological response to the complication. Obama describes the effect of Edith's action in changing his state of demotivation in a successive series of independent clauses in 1-3. His response is reflected in using Edith's words Fired up, ready to go in the coordinated clauses in 1 .

\section{Example 9}

1. After a few minutes, (a) I'm feeling kind of fired up. (b) I'm feeling like I'm ready to go

2. So I start joining in the chant, and my staff starts joining in the chant.

3. And somehow I feel pretty good.

4. And we go on to talk about the lives of the people in the room, and their families and their struggles and their hopes for their kids and their grandkids.

5. And we drive out and it's still raining, but it doesn't seem so bad.

6.(a) And we go to our next stop, and for the rest of the day, (b) even after we left Greenwood, even though we still weren't getting any big crowds anyplace, even though people still couldn't pronounce my name, I felt good. 
Clauses 1 (a) and 1(b) are coordinate clauses with the present progressive verb feeling which belongs to the category of mental verbs (see Table 1) and describes the change of the inner state of Obama, the consequences of which are further described in 4 and 5 . Clause 3 contains its simple present form with the same usage but it is a free clause as it can be placed anywhere in the text without changing the events. In 4, we recalls the sense of collaboration and the achievement of the aim of the visit. In clause 6 , the historical present alternates with the narrative past left because the events in 6(a) and 6(b) are separated by the temporal conjunction even after, implying the separation of the events in the narrative.

\section{Resolution and Coda}

Resolution provides further elaboration following the complication narrating what finally happened while the coda (in Example 10 below) is meant to mark the end of the story and provides a bridge back to the present situation. The following extract marks the end of the story with the proximal deixis here in sentence 1 below:

\section{Example 10}

1. Now, here's the end of the story, though.

2. We knew we were coming back to Des Moines for the last campaign rally I'll ever do for me.

3. And so we were getting kind of sentimental.

4. And we called up Edith Childs.

5. And we said, why don't you come on up?

6. We said, why don't you come on up; we'll fly you up from South Carolina and you can do this chant one more time, just for old good-time sake.

7. It's like getting the band back together again.

8. And you know what Edith said?

9. She said, I'd love to see you, but I think we can still win North Carolina, so I'm taking a crew into North Carolina to knock on doors on Election Day - I don't have time just to be talking about it. I've got to knock on some doors. I've got to turn out the vote. I'm still fired up, but I've got work to do.

10. And that shows you what one voice can do.

It can be assumed that here ties cohesively to part of the resolution that has been reported before in Example 9 and that it answers the hypothetical question in sentence 8 attached as function of the resolution in the narrative. The rest of the resolution is narrated in the sentences that follow and are narratively presented in terms of their events. They are all narrated in past tense except clause $7-$ it is not clear whether it is addressed to the listeners as a comment or a continuation of the reported speech in 6 . Although there are no quotation marks enclosing the speech, we can tell that clause 6 is representing free direct speech because there is no shift in pronouns and tense. It should be noted that the selected texts in the present study are originally written to be 'delivered' texts and here they are analysed as they appeared on the White House website. Therefore, the ambiguity arises because of the full stop at the end of clause 6. However, we can conclude based on the preceding discussion that it is part of the reported utterance for three reasons:

1. When addressing the audience, Obama shifts into present using pragmatic particles such as you know and I think as shown earlier in Examples 3 and 5.

2. The pronoun it is referring back to the request made in the speech reported earlier.

3. The displacement of clause 7 makes it restricted. As the analysis has already shown that the tense shifts into present progressive in restricted clauses, the clause has no shift in tense because it appears to be part of the reported utterance preceding it.

The same argument applies to the underlined sentences following the reporting clause in sentence 9. The distal deixis that in sentence 10 refers back to the resolution reported above and locates the resolution at a distance from Obama and his current situation where he is delivering the speech. It bridges the resolution element with the present moment to denote the current time of Obama as a participant in a conversation addressing the listeners. 


\section{Conclusion}

This study has examined the construction of identity in Obama's narrative through analysing tense shift. The analysis demonstrates that the construction of identity is related to the presentation of the self in narrative discourse. For example, it shows how Obama describes his reaction to events through tense shifts. The study that tense shifts occur in evaluative comments, historical present tends to cluster at the beginning of each scene in narratives and the narrative past alternates with historical present (HP) when Obama reports a change of his emotional and psychological reaction towards unexpected events. The analysis shows that HP occurs in all components of Labov's framework except the abstract. Similarly, investigating the narrative, I have shown that Obama presents himself in the story world through comparing his image to a significant other such as Romney, Edith or the state representatives. Therefore, I have emphasised the necessity of the existence of a 'significant other' (Suleiman, 2006, p. 57) as a fundamental requirement for self-presentation.

\section{References}

Benwell, B. and Stokoe, E. (2006). Discourse and identity. Edinburgh: Edinburgh UP.

Bruner, J. (1990). Acts of Meaning. Cambridge, MA: Harvard UP.

Comrie, B. (1986). 'Tense and time reference: From meaning to interpretation in the chronological structure of a text', Journal of Literary Semantics 15(1): 12-22

Coupland, N. (2001). 'Language, situation, and the relational self: Theorizing dialect-style in sociolinguistics'. In P. Eckert and J. R. Rickford (eds.) Style and Sociolinguistic Variation Cambridge: Cambridge UP, pp. 185-210.

De Fina, A. (2003). Identity in narrative: A study of immigrant discourse (Vol. 3). Amsterdam: John Benjamins.

Fleischman, S. (1991). 'Toward a theory of tense-aspect in narrative discourse'. In J. Gvozdanovic and T. Janssen (eds.) The Function of Tense in Texts. Amsterdam: North-Holland, pp.75-97.

Fludernik, M. (1991). The historical present tense yet again: Tense switching and narrative dynamics in oral and quasi-oral storytelling', Text-Interdisciplinary Journal for the Study of Discourse 11(3): 365-398.

Gimenez, J. C. (2010). 'Narrative analysis in linguistic research'. In L. Litosseliti (ed.) Research Methods in Linguistics. London: Continuum, pp. 198-215.

Hammack, P. L. and Pilecki, A. (2012). 'Narrative as a root metaphor for political psychology', Political Psychology 33(1): 75-103.

Harvey, A. D. (1986). 'Evidence of a tense shift in personal experience narratives', Empirical Studies of the Arts 4(2): 151-162

Labov, W. (1972). 'The transformation of experience in narrative syntax'. In W. Labov (ed.) Language in the inner city: Studies in Black English vernacular. Philadelphia: University of Washington Press, pp. 354-396.

Labov, W. and Waletzky, J. (1967). 'Narrative analysis: oral versions of personal experience'. In J. Helm (ed.) Essays on the verbal and visual arts. Seattle, WA: Washington UP. pp. 12-44.

Linde, C. (1993). Life Stories: The Creation of Coherence. Oxford: Oxford UP.

Ochs, E. and Capps, L (1996). 'Narrating the Self', Annual Review of Anthropology 25: 1943.

Ochs, E. and Capps, L. (2001). Living Narrative. Cambridge, MA: Harvard UP

Reissman, C., K. (1993). Narrative Analysis. London: Sage.

Sarbin, T., R. (1986). 'The Narrative as a Root Metaphor for Psychology'. In T. R. Sarbin (ed.) Narrative Psychology: The Storied Nature of Human Conduct. New York: Praeger, pp. 3-21.

Schiffrin, D. (1981). 'Tense variation in narrative', Language 57: 45-62.

Schiffrin, D. (1996). 'The transformation of experience, identity, and context'. In G. Guy et al.(eds.) Towards a Social Science of Language: Social Interaction and Discourse Structures. Amsterdam: John Benjamins. pp. 41-56.

Suleiman, Y. (2006). 'Constructing languages, constructing national identities'. In T. Omoniyi and G. White (eds.) The Sociolinguistics of Identity. London: Continuum, pp. 50-71. 
Toolan, M. (2001). Narrative: a critical linguistic introduction (2nd edn). London: Routledge. Viney, L. L. and Bousfield, L. (1991). 'Narrative analysis: A method of psychosocial research for AIDS-affected people', Social Science and Medicine 32(7): 757-765.

Voss, J. F., Wiley, J. and Sandak, R. (1999). 'On the use of narrative as argument'. In S.R. Goldman, A.C. Graesser and P. van den Broek (eds.) Narrative comprehension, causality, and coherence: Essays in honor of Tom Trabasso. London: Lawrence Erlbaum, pp. 235-252.

Wolfson, N. (1982). CHP: The conversational historical present in American English narrative (Vol. 1). Walter de Gruyter. 